University of Windsor

Scholarship at UWindsor

\title{
Modeling sampling strategies for determination of zooplankton abundance in ballast water
}

M. R. Hernandez

M. L. Johansson

Y. Xiao

M. A. Lewis

Hugh J. Maclsaac

University of Windsor

Follow this and additional works at: https://scholar.uwindsor.ca/biologypub

Part of the Biology Commons

\section{Recommended Citation}

Hernandez, M. R.; Johansson, M. L.; Xiao, Y.; Lewis, M. A.; and Maclsaac, Hugh J., "Modeling sampling strategies for determination of zooplankton abundance in ballast water" (2017). Marine Pollution Bulletin, $115,2,80-85$.

https://scholar.uwindsor.ca/biologypub/525

This Article is brought to you for free and open access by the Department of Biological Sciences at Scholarship at UWindsor. It has been accepted for inclusion in Biological Sciences Publications by an authorized administrator of Scholarship at UWindsor. For more information, please contact scholarship@uwindsor.ca. 
1 Modeling sampling strategies for determination of zooplankton abundance in ballast water Marco R. Hernandez ${ }^{1 *}$, Mattias L. Johansson ${ }^{1^{*}}$, Yanyu Xiao ${ }^{2,3}$, Mark A. Lewis ${ }^{2}$, and Hugh J. Maclsaac ${ }^{1}$

$5 \quad{ }^{1}$ Great Lakes Institute for Environmental Research, University of Windsor, Windsor, 6 Ontario, Canada;

$7 \quad{ }^{2}$ Department of Mathematical and Statistical Sciences and Department of Biological 8 Sciences, University of Alberta, Edmonton, Alberta

$9{ }^{3}$ Department of Mathematical Sciences, University of Cincinnati, Cincinnati, Ohio $10 \quad$ *Lead authors

12 Corresponding author: Marco Hernandez, GLIER, University of Windsor, Windsor, $13 \quad$ Ontario N9B 3P4 email: hernand2@uwindsor.ca

15 Running title: Sampling strategy for zooplankton in ballast

16 Word count: Abstract: 200, main text: 3976, acknowledgements: 66, references: 725 , 17 tables and figures: 321

18 Keywords: ballast water, modeling, International Maritime Organization, probability density function, sampling effort 


\section{Abstract}

22 Ballast water has been one of the world's largest sources of non-indigenous species

23 introductions. The International Maritime Organization has proposed a performance

24 standard that will establish a numerical limit of $<10$ viable individuals $\mathrm{m}^{-3}$ for

25 zooplankton-sized organisms in discharged ballast. Here we test a variety of sampling

26 efforts for zooplankton-sized organisms in post-exchange ballast water on a commercial

27 vessel. We fit five widely-used probability density functions (PDF) to find the most

28 representative PDF and evaluated sampling efforts necessary to achieve error rates ( $\alpha$,

$29 \beta)$ of $<0.05$. Our tests encompassed four seasonal trials and five sample volumes. To

30 estimate error rates, our simulations drew from 1 to 30 replicates of each volume $(0.10$ -

$313.00 \mathrm{~m}^{3}$ ) for mean densities ranging between 1 and 20 organisms $\mathrm{m}^{-3}$. Field sampling

32 revealed that $>0.5 \mathrm{~m}^{3}$ samples had better accuracy and precision than other volumes

33 tested, and that the Poisson distribution fit these communities best. Simulations of

34 ballast sampling for all PDFs tested also revealed that the optimal and practical sample

35 volume was $>0.5 \mathrm{~m}^{3}$. This study provides the first field test of an alternative sampling

36 strategy to assess compliance with the future IMO D-2 standard that will be applied to

37 all large vessels. 


\section{Introduction}

Ballast water is one of the world's largest vectors for non-indigenous species (NIS) transfer [1]. Efforts to control this vector in the Great Lakes began in 1989 with voluntary mid-ocean ballast water exchange (BWE) for vessels entering with filled ballast-water tanks, which was followed by mandatory regulations in 1993. Regulations were extended to vessels with 'empty' ballast-water tanks in 2006 and 2008 in Canada and the USA, respectively. Ballast water management (BWM) has become a standard procedure worldwide, and is overseen by the International Maritime Organization (IMO). Current IMO best management practises request vessels with full ballast tanks conduct exchange on the open ocean to ensure that $95 \%$ of the ballast volume has been exchanged, to achieve an in-tank salinity of at least $30 \%$ [2]. While this procedure is effective in preventing the movement of NIS between freshwater ports that are connected by transoceanic routes [3], it is less effective when both origin and destination ports are marine [4]. In 2004 the IMO proposed new performance standards (IMO D-2) [5]. This agreement sets numerical limits on the density of two plankton size groups (< 10 viable organisms $\mathrm{m}^{-3}$ for minimum dimension $>50 \mu \mathrm{m}$ and $<10$ viable cells $\mathrm{mL}^{-1}$ for organisms between 10 and $50 \mu \mathrm{m}$ ) as well as for three bacteria indicators [5]. The IMO D-2 convention has yet to be ratified and implemented [5]. Many companies and research groups are testing technology devices and processes to ensure compliance with IMO D-2 standards. Initial steps for approval include testing of devices by an independent third party at verification facilities designed to provide bench-scale estimations, usually referred to as land-based testing. Verification centers also must replicate treatment trials as part of the bench-scale 
63 evaluation. Sampling strategies and sampling effort are intended to be easily replicable

64 [6]. Model ballast tanks must be $\geq 200 \mathrm{~m}^{3}$. For shipboard sampling, control and treated samples need to be collected in triplicate, that uptake and final densities be determined

66 for control tanks, and that viable organism density be assessed before discharge of

67 treated ballast water [7]. However, current guidelines provide no guidance on sample 68 volumes or how they are collected.

Current technology devices have been tested primarily using land-based tests, though a subset have also used shipboard testing [8]. However, no clear method exists

71 for sampling onboard vessels, particularly for sampling directly from ballast tanks. Thus,

72 an imbalance exists in the prescribed sampling process for land-based versus

73 shipboard testing. Onboard sampling poses a major challenge as the IMO D-2 standard

74 requires very low densities of zooplankton, and estimating live density of organisms

75 requires large sample volumes, even under the best case (and unrealistic) scenario that organisms are randomly distributed $[9,10,11]$. Moreover, random dispersion of

77 zooplankton in ballast tanks cannot be assumed, as organisms may aggregate and thus 78 may exhibit a patchy distribution $[12,13]$.

Zooplankton sampling in ballast tanks may be done using plankton nets via

80 hatches $[14,15]$ or, less commonly, by pumping a known volume from the tank into a

81 plankton net [16, 17, 8]. Sampling a ballast tank is complicated as access is limited

82 while in port and very difficult while en route [18]. Samples must be representative of the entire population, easy to replicate, and unbiased. Another consideration is inherent 
accuracy and precision [19]. In addition, the sampling strategy must allow inferences to be made regarding densities of viable zooplankton in treated water.

A number of studies have addressed the effects of low organism density and sample volume on estimating the true density of zooplankton, using both Poisson and negative binomial distributions $[9,10,11,20]$. The validity of this theoretical approach has not yet been affirmed empirically. The Poisson distribution is suitable under the assumption of a centralized outflow that can be sampled entirely or in equal time intervals [13]. A key challenge is access to the entire water column of a tank. Net tows likely introduce bias as only the upper portion of the tank is typically sampled.

In this study, we tested different sampling volumes using three in-tank sampling points to sample the full depth of a ballast tank on a working cargo vessel. Our goal was to identify the sampling efforts that will provide accurate density estimations of zooplankton at the very low abundances that the IMO D-2 standard requires for compliance. We also designed a simple model to contrast common distributions that have been examined theoretically to provide a sample volume that managers can utilize to verify compliance with the IMO D-2 standard.

\section{Methods}

Ballast samples were collected during voyages by the Federal Venture, between 2012 and 2013 [see 21]. The vessel transited from three ports (Saguenay, Trois Rivières, and Bécancour) in Quebec, Canada to two ports (Vila do Conde and Sao Luis) in Brazil. A single trial was conducted during each voyage where samples were taken and analyzed. Samples were collected from the largest ballast tank (Tank 2) on the 
starboard side, with $25 \mathrm{~mm}$ diameter inlet pipes (Alfagomma 266GL Water S\&D PVC Standard Duty) installed at three depths $(4.5,14.5$ and $16.0 \mathrm{~m}$ below top deck level) to account for vertical variation in organism distribution (Fig. 1). We selected those depths based on the geometry of the tank: $4.5 \mathrm{~m}$ is the middle section of the attached wing tank, $14.5 \mathrm{~m}$ is the highest open space in the double-bottom tank, and $16.0 \mathrm{~m}$ is just above the baffle line in the deepest portion of the tank. Each inlet pipe contributed one third of the total sample volume. To assess sampling effort, triplicate samples totalling $0.10,0.25,0.50,1.00$ or $3.00 \mathrm{~m}^{3}$ were collected. Samples were collected two days after ballast-water exchange was performed in the North Atlantic region using a pneumatic, self-priming diaphragm pump. Ballast water was transferred from the tank to the forepeak of the vessel where it was filtered through a $35 \mu \mathrm{m}$ plankton net. Water volume sampled was measured with a Seametrics flowmeter (WMP-Series Plastic-Bodied Magmeter). In-line valves were used to keep water flow rate to $40 \mathrm{~L}$ minute ${ }^{-1}$ in order to avoid mortality due to strong currents. Samples were then fixed in $95 \%$ ethanol for microscope counting. We assumed that all intact individuals encountered when processing under the microscope were alive at the time of capture. Each sample was counted entirely to assess population density. The order in which sample volumes were collected was randomized using a random number generator in Excel (Microsoft Inc.). We conducted basic descriptive statistics (mean and standard deviation) for our four trials. Variance was grouped for fall and spring as those samples were not statistically different and mean densities were similar. Our first goal was to determine the best volume for sampling. Since the true density of organisms in the ballast tank was not known, we assumed that the mean density of organisms over all sample 
131 volumes in each trial was an accurate estimate of true density. Preliminary analysis of 132 variance (ANOVA) revealed that volume sampled had a large impact on the density of

133 organisms in the tank $(p=0.0056)$. We estimated density based on the data points

134 collected from the same volume. We assumed that if we sampled at the same volume 135 repeatedly inside the tank, the density of organisms would follow a given probability 136 distribution function (PDF). We performed the following analysis on each of five PDFs 137 (Poisson, Weibull, Negative binomial, Gamma, and Log-normal) with respect to each

138 volume individually. We estimated the parameters of each PDF by maximum likelihood 139 estimation (MLE). Then, we created random number generators based on the estimated 140 PDFs to sample more data points (i.e. one thousand data points) for the density of 141 organisms for each volume, and calculated the mean square error (MSE) based on our 142 assumption that the true density was the average of density estimates in all trials for 143 each volume [22].

Modeling PDF for distribution of zooplankton

146 Our second goal was to determine how altering the spatial distribution of 147 zooplankton would affect the sampling error rate. Specifically, our objective was to 148 identify the number of samples of a particular volume that would be required to 149 confidently state that a vessel was compliant with the IMO D-2 limit of $<10$ viable 150 organisms $\mathrm{m}^{-3}$ for zooplankton-sized organisms while keeping the rate of Type I and II 151 errors below 5\%. In other words, the cumulative sample number of each individual 152 density (from 1 to 20 organisms $\mathrm{m}^{-3}$ ) required in each scenario was constrained to no 153 more than a 0.05 error rate for both false positives and false negatives. 
We modeled sampling from the ballast tank using a three-dimensional array in $\mathrm{R}$ 155 (R Development Core Team, 2016). To simulate sampling from the tank, we defined each cell of the array as $1 \mathrm{~L}$ of water and the total volume of the array as approximately 157 equal to the actual capacity of the tank used for our sampling $(1,279,400 \mathrm{~L}$ in the actual tank, 1,300,000 L in our model 100×100x130 cell array). For each of 1000 replicates, we 159 populated each cell in the array by drawing randomly from two commonly used PDFs 160 (Poisson and Gamma) with mean densities from 1 to 20 organisms $\mathrm{m}^{-3}$. For each PDF, 161 we then sampled between 1 and 30 replicates using sampling points placed at particular 162 heights in the array (to model our field design) but with randomly assigned length and width coordinates. In each case, we assessed the rate of false positives and false 164 negatives for all combinations of sample volume and replicate number and determined 165 the minimum replicate number required to achieve rates less than $5 \%$.

For the Poisson distribution, we also tested the effect on error rates of having 167 organisms randomly but evenly distributed in the array (Even scenario) at the target 168 density versus organisms preferring the upper wing tank (Uneven scenario: organisms 169 randomly distributed in the $501,400 \mathrm{~L}$ upper section at a much higher density [up to 170 500X higher density] than the 778,000 L lower region while still achieving the same 171 overall density as the even distribution). In addition, we modeled the effect of sampling 172 only from the upper wing tank, as typically occurs in current working vessels. In an ideal 173 Poisson situation with evenly distributed organisms, there should be no difference 174 between sampling a given volume in a single large replicate versus a number of small 175 replicates. However, because our simulations sampled randomly from a distribution, 176 some variance between replicates occurred. 
For the Gamma distribution, we simulated three different distribution shapes to test the effect of variance on our ability to accurately estimate the true density with different sample volumes and replicate numbers. In each simulation, we tested three levels of dispersion by setting the rate to $0.5,1.0$, and 2.0 to correspond with wide, medium, and narrow distributions, respectively, and then stepwise-adjusted the shape to achieve the desired mean, from 1 to 20 organisms $\mathrm{m}^{-3}$.

\section{Results}

Although the vessel traversed essentially the same route from Canada to Brazil during all four trials, the geographic position of ballast-water exchange and subsequent location of sampling varied slightly from one trial to the next. Mean plankton density ranged from 285 to 1170 organisms $\mathrm{m}^{-3}$ (horizontal lines, Fig. 2), with a clear seasonal pattern: trial 1 (July) was highest, trial 3 (November) the lowest, and trials 2 and 4 (September and March) were similar and had intermediate densities (Fig. 2). From our field sampling, it was also evident that dispersion is larger in smaller volumes and that it is generally low at volumes $>0.50 \mathrm{~m}^{3}$ (Fig. 2).

We observed no significant difference fitting the five distribution functions in our MLE for PDFs (Fig. 3), possibly owing to our small empirical dataset (12 data points from each sample volume). We did however note that the $1.00 \mathrm{~m}^{3}$ sampling volume exhibited the lowest MSE term relative to other volumes tested (Table 1).

When organisms were evenly Poisson distributed in the ballast tank, simulations exhibited a clear relationship between sample volume, replicate number, and our ability to confidently state whether the ballast tank was compliant or not. As mean density of 
200 the sample approached the permissible limit of 10 organisms $\mathrm{m}^{-3}$, the total volume of

201 samples required to assess compliance also increased (Fig. 4, upper panel).

202 Consequently, smaller sampling volumes reached our arbitrary limit of 30 replicates

203 earlier than did larger ones, leading to a larger window where sample sizes were

204 insufficient to confidently assess compliance. For example, a single $0.10 \mathrm{~m}^{3}$ sample

205 (pink dotted line, Figure 6 upper panel) could be sufficient to identify the sample as

206 compliant (i.e. $<10$ organisms $\mathrm{m}^{-3}$ ) if the true density was below 3 organisms $\mathrm{m}^{-3}$,

207 though the number of replicates required at this volume exceeds 30 if true density was

$208>7$ organisms $\mathrm{m}^{-3}$. To avoid incorrectly declaring a sample compliant when the true

209 density is at or above 10 organisms $\mathrm{m}^{-3}$, more than 30 samples of size $0.10 \mathrm{~m}^{3}$ would

210 be required if the true density ranged between 10 and 14 organisms $\mathrm{m}^{-3}$ (i.e. just above

211 the permissible limit). Increasing the volume of samples improves our ability to

212 confidently assess compliance as the true density approaches the 10 organisms $\mathrm{m}^{-3}$

213 limit (dotted vertical line, Fig. 4, upper panel).

214 In contrast to small volume samples, those of $3.00 \mathrm{~m}^{3}$ required three or fewer

215 replicate samples to confidently determine compliance when the true density was below

2168 organisms $\mathrm{m}^{-3}$ or above 12 organisms $\mathrm{m}^{-3}$ (red long dash line, Fig. 4 upper panel), and

217 compliance could be assessed with 11-12 replicates if true density was very close to the

218 maximum permissible limit (i.e. 9 or 11 organisms $\mathrm{m}^{-3}$ ). Intermediate sample sizes could

219 be used to confidently assess compliance when the true density was $<7$ or $>13$

220 organisms $\mathrm{m}^{-3}$, but as sample volume declined, the number of replicates required

221 increased (Fig. 4, upper panel). As expected, across the range of densities tested, total

222 sample volume seemed to be the key determinant of our ability to confidently assess 
223 compliance when organisms were evenly Poisson distributed. For example, at a true

224

225

226

227

228

229

230

231

232

233

234

235

236

237

238

239

240

241

242

243

244

245 density of 7 organisms $\mathrm{m}^{-3}$, compliance could be assessed with a minimum of $24,9,5,3$ or 1 sample(s) for volumes of $0.10,0.25,0.50,1.00$, or $3.00 \mathrm{~m}^{3}$, respectively.

When organisms were unevenly distributed and were sampled from the full depth of the ballast tank (all three sampling ports), we saw a very similar pattern, though it moved the window of non-confidence (error rate $>0.05$ ) toward false negatives (Fig. 4 , lower panel). All volumes except for $0.10 \mathrm{~m}^{3}$ could be used to assess compliance when the true density of organisms was $\leq 9$ organisms $\mathrm{m}^{-3}$ (pink dotted line, Fig. 4, lower panel); however, when the sample volume was low (e.g. $0.25 \mathrm{~m}^{3}$ ), a large (20) number of replicates was required (green dashed line). The number of replicates required to confidently assess compliance dropped progressively from 8 to 4 to 2 replicates at 0.50 , 1.00 and $3.00 \mathrm{~m}^{3}$ (blue dash dot dash, yellow solid, red long dash lines, respectively). The lower total volume required for samples of $1.00 \mathrm{~m}^{3}\left(4 \mathrm{~m}^{3}\right)$ versus $3.00 \mathrm{~m}^{3}\left(6 \mathrm{~m}^{3}\right)$ suggests that multiple $1.00 \mathrm{~m}^{3}$ samples might be the most tractable sampling scheme, given the time required to process samples under the microscope. The major difference between "uneven" and "even" scenarios is that there were more true densities above the compliance limit where we could not confidently assess compliance in the former scenarios. At a density of 13 organisms $\mathrm{m}^{-3}$, we could confidently assess compliance with sample volumes of $1.00 \mathrm{~m}^{3}$ (yellow solid line) and $3.00 \mathrm{~m}^{3}$ (red long dash line), but both required sampling impractically large volumes of water: $20 \mathrm{~m}^{3}$ (20 samples) for $1.00 \mathrm{~m}^{3}$ and $18 \mathrm{~m}^{3}$ (6 samples) for $3.00 \mathrm{~m}^{3}$.

In the uneven Poisson scenario, where organisms were concentrated in the top section of the tank and only that region was sampled, (Fig. 4, lower panel) results were 
246 quite different. As organism density in the upper portion of the tank was much higher

247 than the overall mean density, it was very easy to overestimate mean density;

248 consequently, large sample volumes from tanks with low overall density (i.e. $<3$

249 organisms $\mathrm{m}^{-3}$ ) were required to achieve an acceptable rate of false positives. In

250 contrast, it took relatively small sample volumes (i.e. $1.00 \mathrm{~m}^{3}$ total from any sample

251 volume/replicate combination) to avoid false negatives, as few samples estimated

252 densities lower than 10 organisms $\mathrm{m}^{-3}$.

253 Similar to the Poisson results sampled from throughout the tank, all sampling

254 volumes with the Gamma PDF had a window of non-confidence for densities

255 approaching the IMO D-2 standard of 10 organisms $\mathrm{m}^{-3}$. Overall, the relationships

256 between different sample sizes was similar to that seen in the Poisson model, above. In

257 all three dispersion scenarios, larger samples had narrower ranges where we failed to

258 confidently assign compliance with reasonable replicate numbers (i.e. <30 replicates;

259 Fig. 5). In the Gamma simulations, the key difference among the three different

260 dispersion scenarios is that as dispersion decreased (rate increased), the range where

261 we could not confidently assign compliance narrowed. This was most apparent in the

262 smallest sample size $\left(0.10 \mathrm{~m}^{3}\right.$, Fig. 5, pink dotted line). In the highest dispersion

263 (rate=0.5) model, we failed to confidently assign compliance for true densities from 7 to

26415 organisms $\mathrm{m}^{-3}$, while for the intermediate dispersion (rate=1.0) model the range is 8

265 to 14 organisms $\mathrm{m}^{-3}$, and for the more aggregated organisms (rate=2.0) model the

266 range is 9 to 12 organisms $\mathrm{m}^{-3}$. The other sample volumes tested exhibited a similar, if

267 less pronounced, pattern. The other major difference was that the number of replicates

268 for a given volume decreased with decreasing statistical dispersion. This was very 
269 pronounced in the $3.00 \mathrm{~m}^{3}$ sample size, which maintained the same narrow range of

270 non-confidence throughout all three rate scenarios, but required $>20$ replicates for

271 confidence when dispersion was highest, 10-12 replicates at intermediate dispersion,

272 and 5-6 replicates when dispersion was low (Fig. 5, red long dash line). This pattern of a

273 narrowing of the non-confidence range with decreasing dispersion, and a decrease in

274 replicates required for confidence, was consistent across all five sample volumes.

275 Consistent with the Poisson model, the largest sample sizes again returned the

276 narrowest range of non-confidence for tractable sample numbers.

\section{Discussion}

279 Even at very low densities, sampling volumes of 1.00 and $3.00 \mathrm{~m}^{3}$ were able to 280 accurately estimate zooplankton density in ballast tanks. However, the improvement in 281 accuracy by adding additional samples was more practical for $1.00 \mathrm{~m}^{3}$ than for $3.00 \mathrm{~m}^{3}$ 282 samples. The $1.00 \mathrm{~m}^{3}$ samples had the lowest MSE scores in five out of six PDFs tested 283 (all except Log-normal), and were, therefore, the most accurate of all volumes tested 284 (Table 1 and Fig. 3).

285 Sampling across the water column addresses problems inherent in sampling 286 species with patchy distributions, and is required for testing IMO D-2 compliance [6, 12]. 287 Individual zooplankton tend to aggregate in natural waters [13] and likely do so in ballast 288 tanks as well. Our multiport sampling design allowed us to sample the entire water 289 column, including the double-bottom portion, which is usually inaccessible. Thus, 290 multiple sampling ports provide more accurate estimates of organism density than 291 single ports or if researchers use deck-based plankton nets. Although we used an equal 
292 number of ports as Murphy et al. [12], our design allowed us to collect water from the

293 lower portion of the tank, which is inaccessible to open hatch tow sampling. It also made

294 possible to take as many replicate samples as desired within a short period of time

295 without affecting vessel operations.

The Poisson distribution had the lowest MSE scores in all volumes (Table 1). The

297 results we obtained were similar for Gamma distribution in deriving the likelihood of over

298 dispersion due to clumping. The Poisson distribution is commonly used for modeling

299 zooplankton distributions in ballast tanks [9, 10, 11, 20], however, the Gamma

300 distribution also has been used as a Poisson approximation. Gamma distribution

301 estimates abundance distributions [23] and has been suggested for zooplankton in

302 ballast water [20]. A need exists to build data sets that allow identification of an

303 appropriate PDF based on empirical data. Our attempt with a rather limited data set

304 proved inconclusive.

True zooplankton densities were not known in our trials, thus we relied on a

series of assumptions that justified using the mean of all sampling efforts per trial.

307 Under these assumptions, large volume samples had higher precision and lower

308 variability. Trials 1 and 3 also demonstrated that the largest volume $\left(3.00 \mathrm{~m}^{3}\right)$ estimated

309 density better than smaller ones. However, in Trials 2 and 4 large volumes

310 underestimated densities. While larger volumes - such as $3.00 \mathrm{~m}^{3}$ - provided- in

311 general- better estimates, they increased work load prohibitively and thus cannot be

312 recommended (see [11]). We observed that $1.00 \mathrm{~m}^{3}$ samples had the lowest MSE and

313 provided a good estimation with a low rate of false positives when organism abundance

314 was $\leq 10$ individuals $\mathrm{m}^{-3}$, and a low false negative rate when density $\geq 10$ individuals $\mathrm{m}^{-3}$ 
315 for the two PDFs evaluated here. The error rate can be improved for estimates based 316 on $1.00 \mathrm{~m}^{3}$ samples by increasing the number of replicates (Figs. 5 and 6). Because our

317 sampling technique was already an integration of three equal volumes, even a single

318 replicate enhanced accuracy of the density estimate, and replicates at this volume are 319 manageable.

There exists support for the argument that large volume samples offer better 321 estimations assuming Poisson-based models (e.g. see $[9,10])$. However when the 322 dispersion of organisms in the tank is unknown, there is a possibility to overestimate 323 densities and wrongly conclude that vessels are not in compliance with the IMO D-2 324 standard (see Fig. 4). In our 'uneven' Poisson simulations, altering how animals are 325 distributed in the tank modified not only the proportion of false positives and negatives, 326 but the capability to accurately assess organism densities at all tested volumes. We 327 agree with the aforementioned authors that larger volumes $\left(e . g 7.00 \mathrm{~m}^{3}\right)$ provide a 328 better estimator of density, though these volumes are impractical for organism 329 enumeration at anything other than, and possibly including, a land-based testing facility. 330 Our three sampling port design provides better opportunities to accurately quantify 331 plankton present at low density.

332 Our descriptive statistics highlighted that dispersion was larger on small sample 333 volumes and decreased as volume increased (Fig. 2). Despite the non-significant 334 difference among sampling volumes, we observed that sampling volumes below 0.50 $335 \mathrm{~m}^{3}$ are much more variable and thus less reliable (Fig. 2). Our comparison of MSE 336 scores for all trials and volumes demonstrated that $1.00 \mathrm{~m}^{3}$ had the smallest MSE and 337 thus the best accuracy. 
The two PDFs that we used to simulate sampling allow us to infer that when

339 zooplankton populations are present at low densities, both 1.00 and $3.00 \mathrm{~m}^{3}$ sample

340 volumes provide good estimates of density with acceptable error rates $(<0.05)$ versus

341 smaller volumes.

342 Our study is limited by the number of trials and replicates within each sample

343 volume, however it presents realistic working conditions and constraints likely to be

344 encountered on ocean-going vessels. Validation procedures for IMO D-2 standard are

345 in development. At present there exist no clear guidelines on sample volumes or sample

346 number. We suggest $1.00 \mathrm{~m}^{3}$ as a starting point and encourage collection of additional

347 empirical data and assessment of sampling strategies.

348 Empirical data highlighted that integrative samples added precision to density

349 estimations by reducing variance, and that large but practicable volumes - such as 1.00

$350 \mathrm{~m}^{3}$ - benefit from it. MSE scores for $1.00 \mathrm{~m}^{3}$ were lowest regardless of which PDF was

351 used to fit our data, suggesting that this volume most accurately estimated true density.

352 Finally, our simulations revealed that increasing the size and number of samples

353 improves confidence in compliance assessments, with the best tradeoff between

354 accuracy and precision and work load seemingly optimized with $1.00 \mathrm{~m}^{3}$ samples.

356 Author Contributions

$357 \mathrm{MRH}, \mathrm{MLJ}$ and HJM designed the study and wrote the paper, MLJ, YX and MAL 358 conducted simulations, and all authors edited the manuscript. 
We are grateful to Fednav Inc. and the captains and crews of the Federal

362 Venture for assistance in preparing and executing onboard experiments. Lab assistance was provided by Vishal Vara and Lucas Wilson. We acknowledge funding from Fednav

364 Inc. and the NSERC CAISN network, and NSERC Discovery grants and Canada

365 Research Chairs to M.A.L. and H.J.M. M.R.H. was supported by a scholarship from 366 CONACyT Mexico.

\section{References}

1. Molnar, J. L., Gamboa, R. L., Revenga, C., \& Spalding, M. D. (2008). Assessing the global threat of invasive species to marine biodiversity. Frontiers in Ecology and the Environment, 6, 485-492.

2. IMO. (2008b) Guidelines for ballast water exchange (G6) [Internet]. London, United Kingdom: International Maritime Organization [accessed 2015 December 7].

4. Wonham, M. J., Walton, W. C., Ruiz, G. M., Frese, A. M., \& Galil, B. S. (2001). Going to the source: role of the invasion pathway in determining potential invaders. Marine Ecology Progress Series, 215, 1-12.

5. International Maritime Organization (IMO). (2004). International convention for the control and management of ships' ballast water and sediments [Internet]. London, 
United Kingdom: International Maritime Organization [accessed 2015 December 7]. Available from http://www.imo.org/en/About/Conventions/ListOfConventions/ Pages/International-Convention-for-the-Control-and-Management-of-Ships'Ballast-Water-and-Sediments-(BWM).aspx

6. IMO. (2008a) Guidelines for ballast water sampling (G2) [Internet]. London, United Kingdom: International Maritime Organization [accessed 2015 December 7]. Available from http://globallast.imo.org/wp-content/uploads/2015/01/G2GUIDELINES-FOR-BALLAST-WATER-SAMPLING.pdf

7. IMO. (2008c) Guidelines for approval of ballast water management systems (G8). London, United Kingdom: International Maritime Organization [accessed 2015 December 7]. Available from http://globallast.imo.org/wpcontent/uploads/2015/01/G8-GUIDELINES-FOR-APPROVAL-OF-BALLASTWATER-MANAGEMENT-SYSTEMS.pdf

8. Gollasch, S., \& David, M. (2010). Testing sample representativeness of a ballast water discharge and developing methods for indicative analysis. European Maritime Safety Association (EMSA). Report No. 4.

9. Lee II, H., Reusser, D.A., Frazier, M., \& Ruiz, G. (2010). Density Matters: Review of Approaches to Setting Organism-Based Ballast Water Discharge Standards. U.S. EPA, Office of Research and Development, National Health and Environmental Effects Research Laboratory, Western Ecology Division. EPA/600/R-10/031. 10. Miller, A. W., Frazier, M., Smith, G. E., Perry, E. S., Ruiz, G. M., \& Tamburri, M. N. (2011). Enumerating sparse organisms in ships' ballast water: why counting to 10 is not so easy. Environmental Science \& Technology, 45, 3539-3546. 
407

408

409

410

411

412

413

414

415

416

417

418

419

420

421

422

423

424

425

426

427

428

11. Frazier, M., Miller, A. W., Lee, H., \& Reusser, D. A. (2013). Counting at low concentrations: the statistical challenges of verifying ballast water discharge standards. Ecological Applications, 23, 339-351.

12. Murphy, K. R., Ritz, D., \& Hewitt, C. L. (2002). Heterogeneous zooplankton distribution in a ship's ballast tanks. Journal of Plankton Research, 24, 729-734.

13. First, M. R., Robbins-Wamsley, S. H., Riley, S. C., Moser, C. S., Smith, G. E., Tamburri, M. N., \& Drake, L. A. (2013). Stratification of living organisms in ballast tanks: how do organism concentrations vary as ballast water is discharged? Environmental Science \& Technology, 47, 4442-4448.

14. Briski, E., Bailey, S. A., Casas-Monroy, O., DiBacco, C., Kaczmarska, I., Lawrence, Nasmith, L. E. (2013). Taxon-and vector-specific variation in species richness and abundance during the transport stage of biological invasions. Limnology and Oceanography, 58, 1361-1372.

15. Simard, N., Plourde, S., Gilbert, M., \& Gollasch, S. (2011). Net efficacy of open ocean ballast water exchange on plankton communities. Journal of Plankton Research, 33, 1378-1395.

16. McCollin, T., Shanks, A. M., \& Dunn, J. (2008). Changes in zooplankton abundance and diversity after ballast water exchange in regional seas. Marine Pollution Bulletin, 56, 834-844.

17. Veldhuis, M. J., Fuhr, F., Boon, J. P., \& Ten Hallers-Tjabbers, C. C. (2006). Treatment of ballast water; how to test a system with a modular concept? Environmental Technology, 27, 909-921. 
429 18. Wright, D. A., \& Mackey, T. P. (2006). Shipboard and dockside trials of ballast water

430

431

432

433

434

435

436

437

438

439

440

445

446

447 treatment technology. Naval Engineers Journal, 118, 37-43.

19. Lemieux, E. J., Robbins, S., Burns, K., Ratcliff, S., \& Herring, P. (2008). Evaluation of representative sampling for rare populations using microbeads (No. CG-D-0308). Coast Guard Washington DC Office of Research and Development.

20. Costa, E. G., Lopes, R. M., \& Singer, J. M. (2015). Implications of heterogeneous distributions of organisms on ballast water sampling. Marine Pollution Bulletin, 91, 280-287.

21. Paolucci, E. M., Hernandez, M. R., Potapov, A., Lewis, M. A., \& Maclsaac, H. J. (2015). Hybrid system increases efficiency of ballast water treatment. Journal of Applied Ecology, 52, 348-357.

22. Walther, B. A., \& Moore, J. L. (2005). The concepts of bias, precision and accuracy, and their use in testing the performance of species richness estimators, with a literature review of estimator performance. Ecography, 28, 815-829.

23. Engen, S., \& Lande, R. (1996). Population dynamic models generating species abundance distributions of the gamma type. Journal of Theoretical Biology, 178, 325-331. 
448 Table 1. Mean squared error $\left(\mathrm{MSE}^{*} 10^{-5}\right)$ computed for each probability density function 449 and each volume $\left(\mathrm{m}^{3}\right)$. Lower values indicate less dispersion between data points and the distribution curve.

\begin{tabular}{|c|c|c|c|c|c|}
\hline $\begin{array}{c}\text { Volume } \\
\left(\mathrm{m}^{3}\right)\end{array}$ & Poisson & Weibull & $\begin{array}{c}\text { Negative } \\
\text { Binomial }\end{array}$ & Gamma & Log-normal \\
\hline 0.10 & 1.2981 & 2.5946 & 2.5350 & 2.5364 & 2.7047 \\
\hline 0.25 & 2.0119 & 3.9496 & 4.0674 & 4.0826 & 4.7422 \\
\hline 0.50 & 1.6707 & 3.2963 & 4.0197 & 4.1046 & 6.3578 \\
\hline 1.00 & 0.7853 & 1.5300 & 1.7222 & 1.7800 & 2.3707 \\
\hline 3.00 & 1.4096 & 2.8947 & 3.2303 & 3.2271 & 5.5991 \\
\hline
\end{tabular}

451

452 


\section{$453 \quad$ List of Figures}

454 Figure 1: Location of sampling ports inside the ballast tank.

455 Figure 2: Densities estimated from all four trials and five sampling efforts. Markers

456 (diamonds - Trial 1, squares - Trial 2, triangles - Trial 3, and circles - Trial 4)

457 indicate mean volume $(n=3) \pm$ one standard deviation.

458 Figure 5: Box and whisker plot for maximum likelihood of six probability density function $459 \quad$ testing $1.00 \mathrm{~m}^{3}$ sample volumes.

460 Figure 6: Minimum sample numbers required at a given animal density and sample 461 volume to achieve $<5 \%$ false positive/false negative rate for Poisson-distributed 462 organisms. False positives are shown to the left of the midline, false negatives to the 463 right. The central gap indicates that the minimum sample number required exceeds 464 our arbitrary cutoff of 30 replicates at a given volume. The upper panel represents a case where organisms are evenly distributed throughout the tank. Middle panel shows the case where organisms favor the upper $1 / 3$ of the tank and sampling is through three sampling ports (as in our field experiment). In the bottom panel, organisms are aggregated in the upper $1 / 3$ of the tank and sampling is restricted to the upper portion of the tank.

Figure 7: Minimum sample numbers required at a given animal density and sample volume to achieve $<5 \%$ false positive/false negative rate for Gamma-distributed organisms. False positives are shown to the left of the midline, false negatives to the 
476

477

478

\section{Midship section}

479

480

481 Figure 1.

482

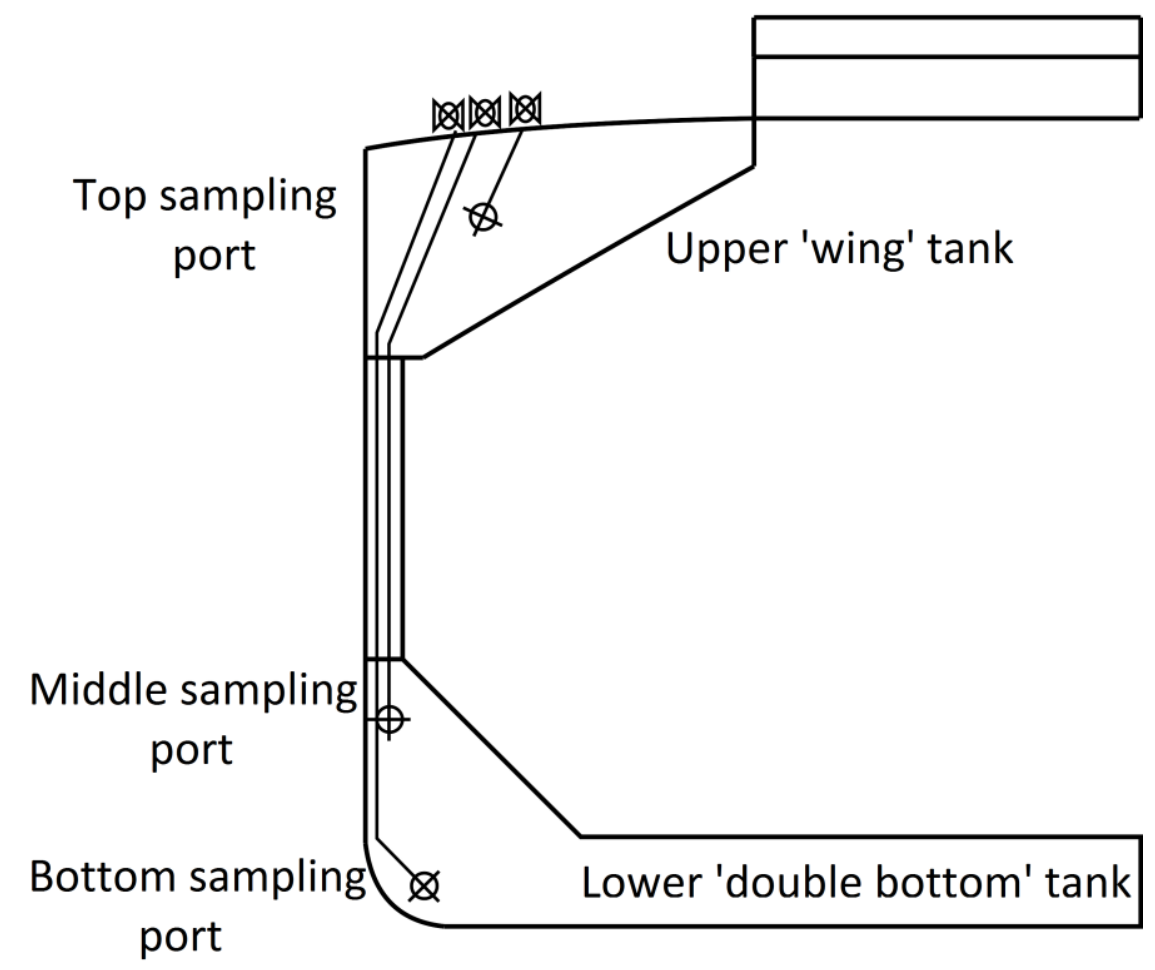


483

484

485

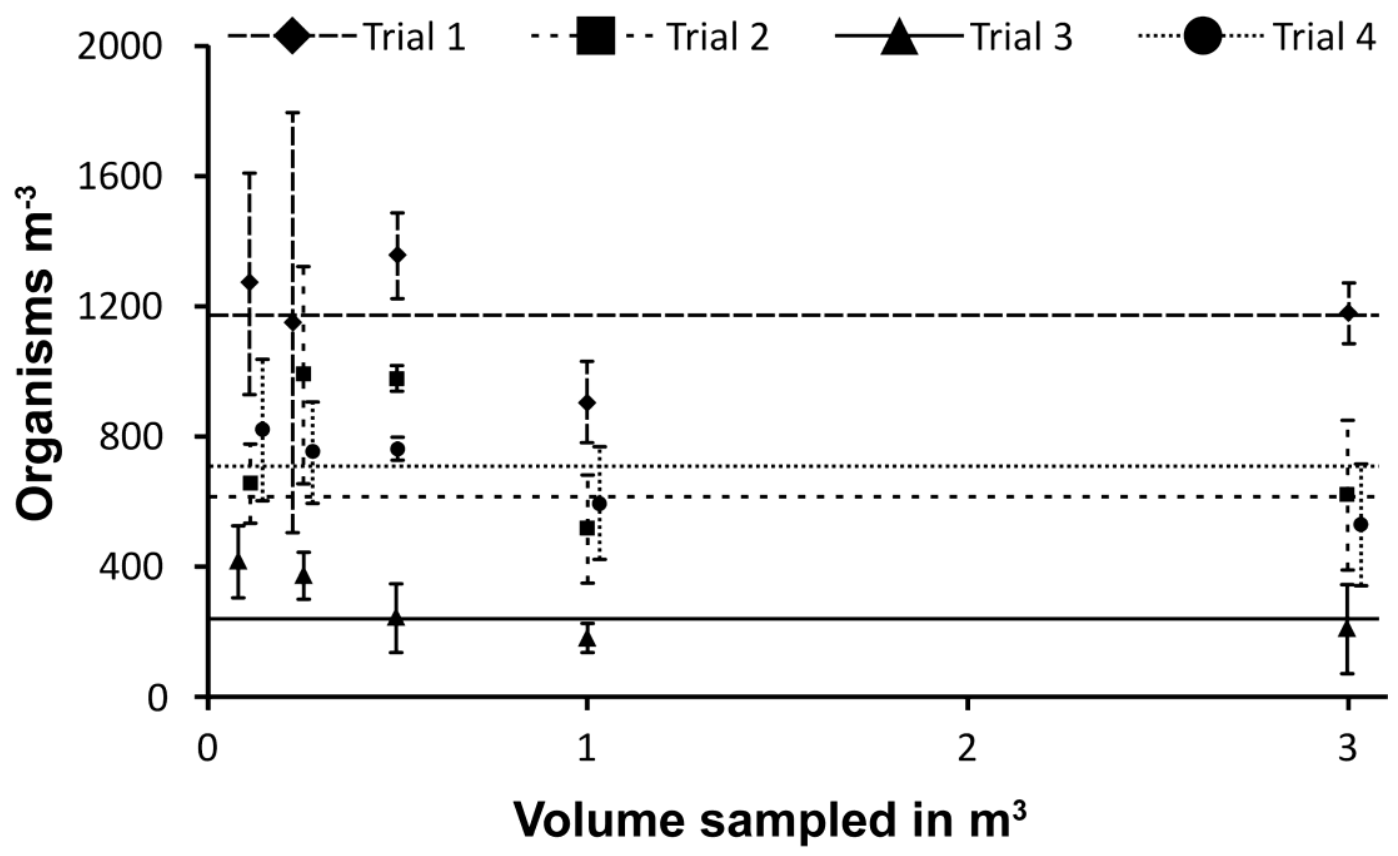

488 Figure 2.

489 
490

491

492

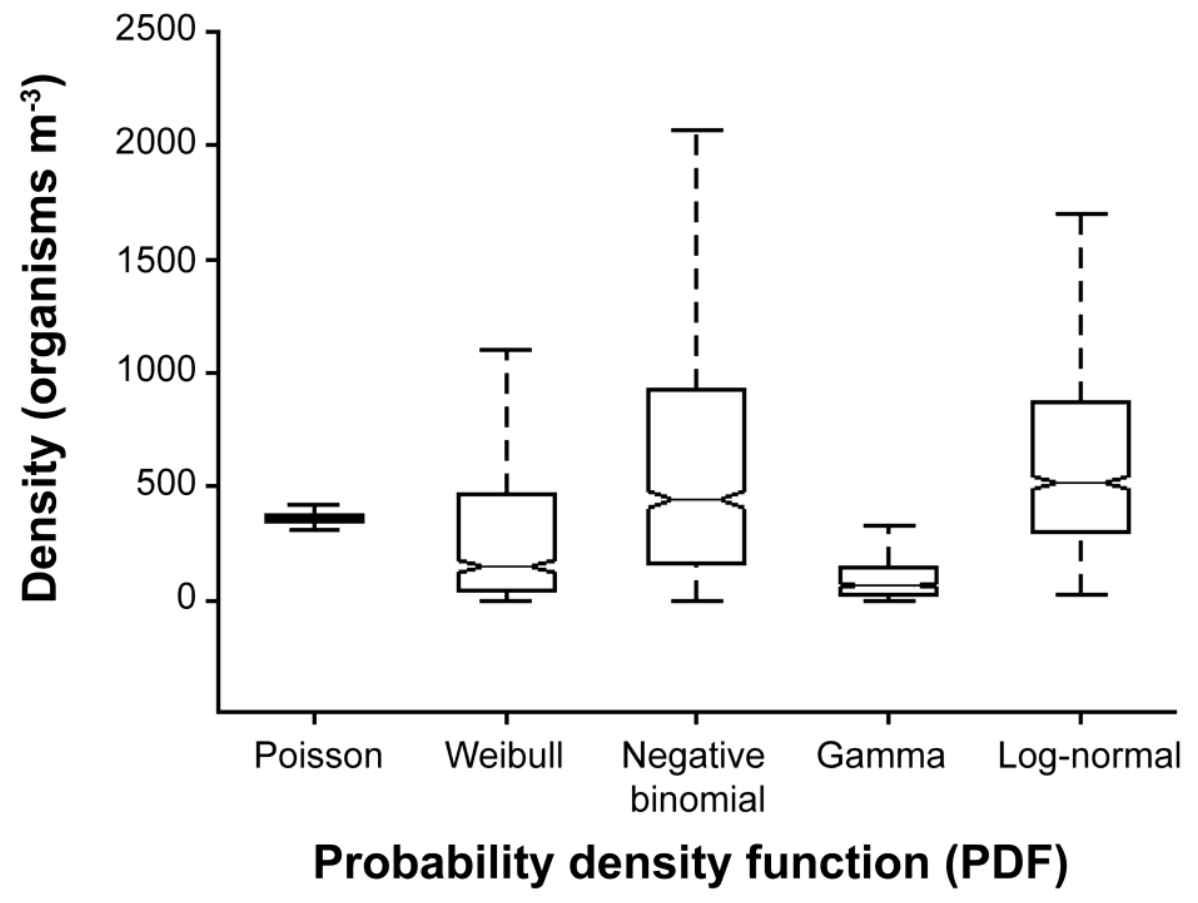

494

495 Figure 3.

496 


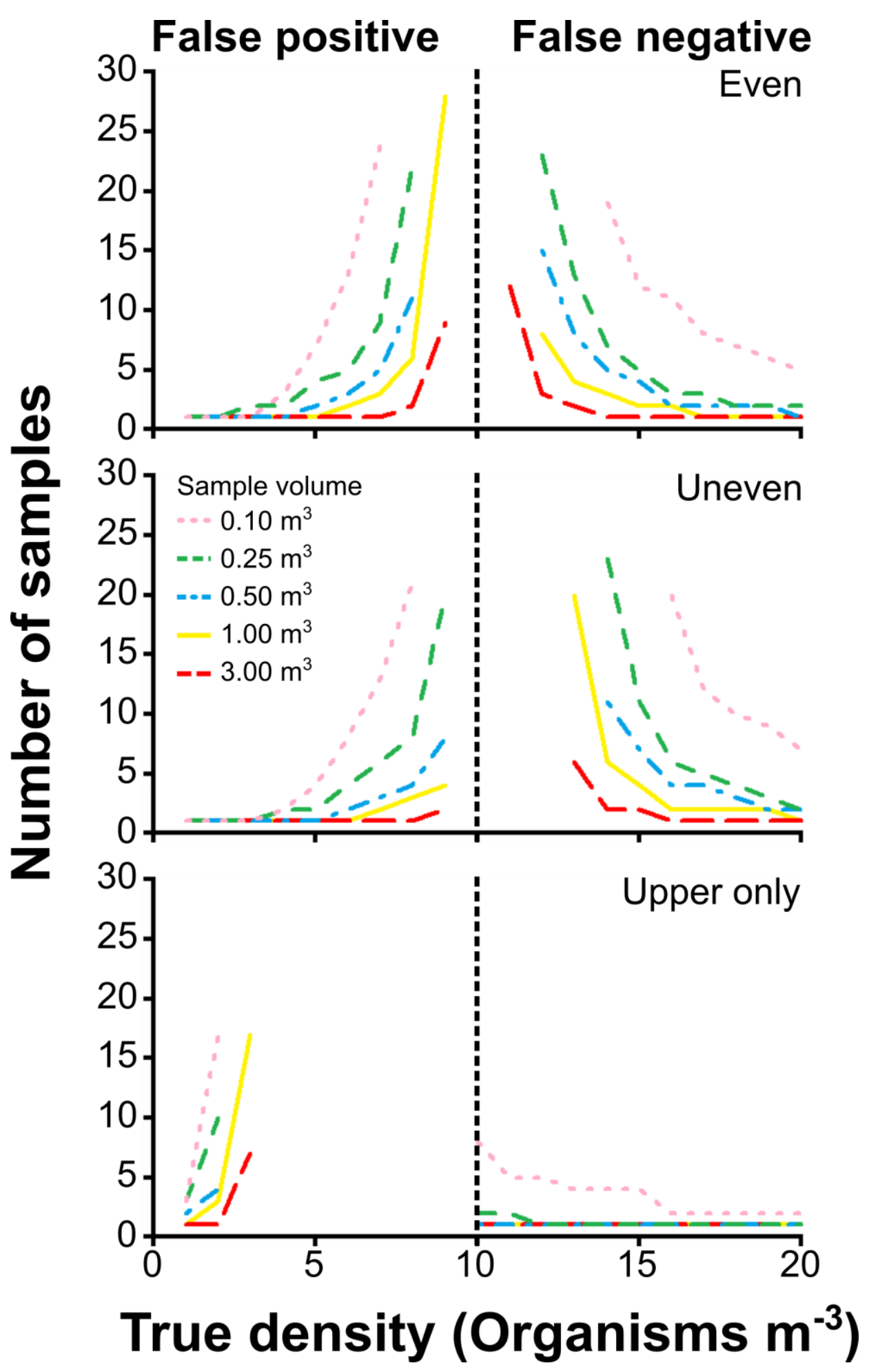




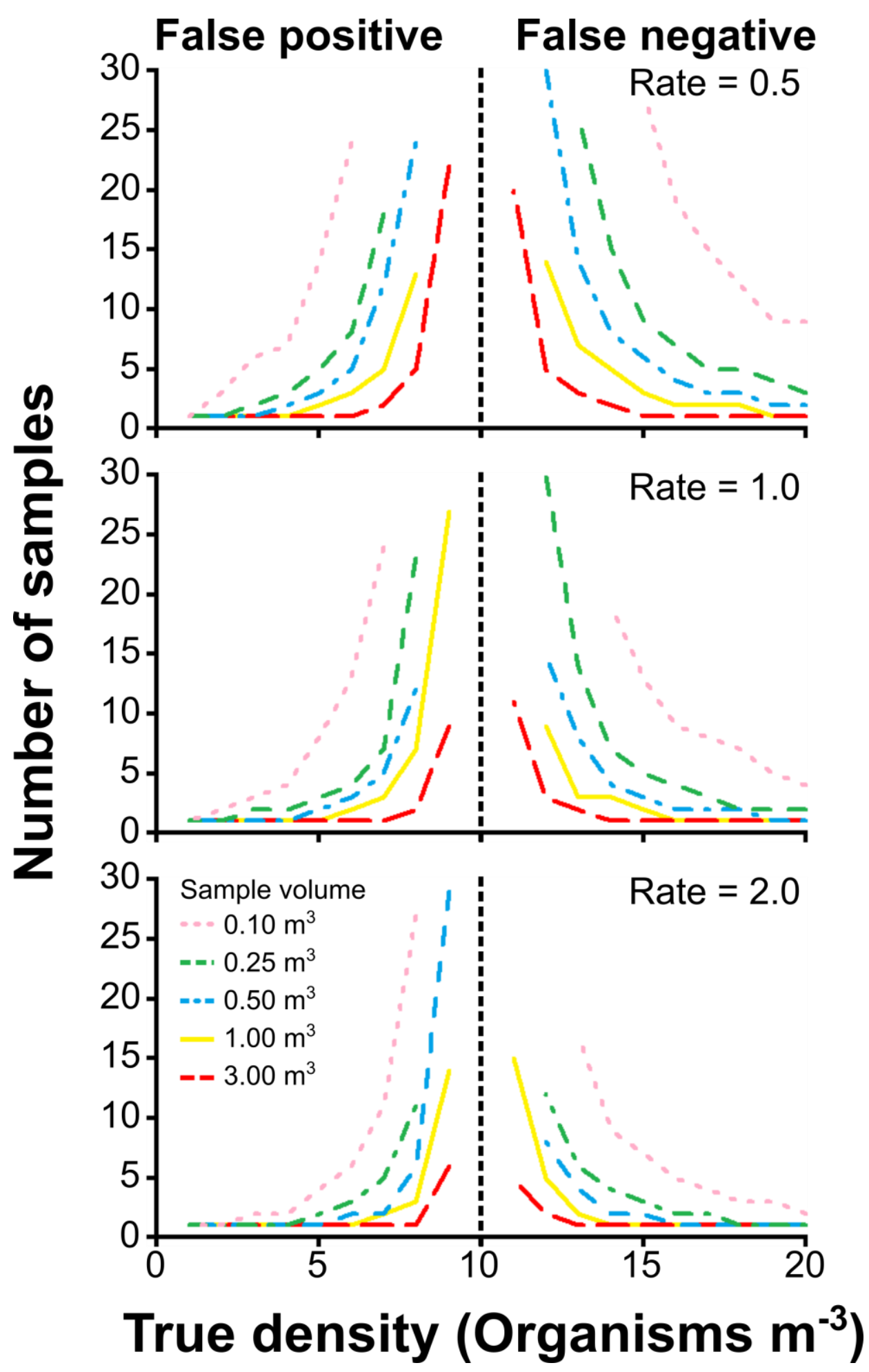

